\title{
Revista de Oncología en MEDLINE/Index Medicus
}

Es una gran satisfacción para el Comité Editorial de Revista de Oncología transmitir a los socios de FESEO y del INCAN, y en general a nuestros lectores, la noticia de que la National Library of Medicine de Ios EE.UU. de América ha aceptado citarla e indizarla en MEDLINE y en Index Medicus.

Este éxito viene avalado por el enorme esfuerzo colectivo en el que han participado todas las sociedades de la FESEO y el INCAN, junto con una amplísima representación de las comunidades oncológicas de España y México. Desde estas líneas, el Equipo de Dirección y Redacción de la revista quiere agradecer a todos los autores que con sus aportaciones en forma de revisiones, artículos, notas clínicas y cartas, han hecho posible la publicación de Revista de Oncología en estos últimos años con la periodicidad y la calidad científica necesarias para llegar a ser incluidos en este prestigioso índice bibliográfico.

Nuestro agradecimiento va también dirigido muy especialmente a los revisores que de forma brillante y eficaz han realizado una labor silenciosa y anónima, pero esencial, en la valoración de todos los artículos recibidos para su evaluación. Sus comentarios y críticas han sido de una gran utilidad para seleccionar los mejores artículos para su publicación, y para mejorar la calidad científica de los artículos publicados. Sin la ayuda de este pequeño ejército de colaboradores hubiera sido imposible realizar esta ingente labor, con casi 700 artículos evaluados hasta la fecha.

El resultado final de este proceso, que comenzó sus primeros pasos en enero de 1999, es un gran estímulo para continuar nuestra labor de mejora continuada de la revista. Más que un punto de llegada, este reconocimiento supone un punto de partida que nos permitirá conseguir la revista que FESEO y el INCAN quieren tener. Sin duda, Revista de Oncología puede constituirse en el crisol donde se fragüe la fusión de toda la oncología iberoamericana. Será un mérito y una responsabilidad de todos los miembros de FESEO y del INCAN conseguir que Revista de Oncología sea incluída en el Journal of Citation Reports en una digna posición dentro del ámbito de la oncología. Para ello, no solo debemos colaborar con el envío de nuestros trabajos, sino que debemos convertir a Revista de Oncología en una herramienta esencial de trabajo cotidiano y favorecer su difusión a nivel internacional.

¡Enhorabuena a todos y gracias por vuestra colaboración!.

Equipo de Dirección y Redacción 